\title{
TRIMETHOPRIM - SULFAMETHOXAZOLE IN COMBINATION WITH MEROPENEM ORPOLYMYXIN IS EFFECTIVE IN MANAGEMENT OF ACINETOBACTER BAUMANNII ASSOCIATED PNEUMONIA AND URINARY TRACT INFECTION
}

\author{
Keyal NK', Nepal $N^{2}$, Bhujel $A^{1}$
}

\begin{abstract}
Affiliation
1. Department of Critical Care Medicine, B \& C Medical College and Teaching Hospital and Research Center, Birtamode, Nepal.

2. Department of Anaesthesiology and Critical care, B \& C Medical College and Teaching Hospital and Research Center, Birtamode, Nepal.
\end{abstract}

\section{ARTICLE INFO}

Received : 06 June, 2019

Accepted : 25 January, 2020

Published : 30 June, 2020

(C) Authors retain copyright and grant the journal right of first publication with the work simultaneously licensed under Creative Commons Attribution License CC - BY 4.0 that allows others to share the work with an acknowledgment of the work's authorship and initial publication in this journal.

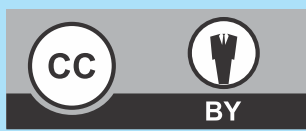

CR 30

DOI: https://doi.org/10.3126/bjhs.v5i1.29640

* Corresponding Author

Dr Niraj Kumar Keyal

Lecturer

Department of Critical Care Medicine

B \& C Medical College and Teaching Hospital and Research Center Birtamode, Nepal

Email: nirajkumarkeyal@gmail.com

ORCID ID: https://orcid.org/0000-0001-8587-1718

\section{Citation}

Keyal NK, Nepal N, Bhujel A, Trimethoprim - Sulfamethoxazole in Combination with Meropenem Orpolymyxin is Effective in Management of Acinetobacter Baumannii Associated Pneumonia and Urinary Tract Infection. BJHS 2020;5 (1)11:991-995.

\section{ABSTRACT}

Acinetobacter baumanniiis a common multidrug resistant bacteria that causes pneumonia and urinary tract infection in intensive care unit and requires dual antibiotic for effective management. There are limited expensive antibiotics that are active against. Acinetobacter baumannii. Trimethoprim - Sulfamethoxazole is a cheap, older and easily available antibiotic that can be used in combination with Meropenem or Polymyxin fortreatment to decrease antibiotic resistance. This case presentation of three patients describes the successful treatment of hospital acquired Pneumonia and Urinary Tract Infection by Acinetobacter baumannii with Trimethoprim - Sulfamethoxazole in combination with Meropenem and Polymyxin that lead avoidance of costly drugs and decrease in antibiotic resistance. Antibiotic resistance and lack of newer effective antibiotic against multidrug resistant bacteria like Acinetobacter baumannii is a common problem in intensive care unit. Trimethoprim -Sulfamethoxazole may help in combating this problem.

\section{KEYWORDS}

Acinetobacter baumannii, pneumonia, trimethoprim and sulfamethoxazole, urinary tract. 


\section{INTRODUCTION}

Acinetobacter baumannii is a multidrug resistant (MDR) opportunistic gram negative coccobacilli that commonly causeshospital acquired $^{[1]}$ but rarely it may also cause community acquired ${ }^{[2]}$ pneumonia, urinary tract infection, endocarditis, meningitis, wound infection.

It is $\mathrm{MDR}^{[3]}$ bacteria that is resistance to most of commonly used antibiotics therefore combination therapy is used to decrease antibiotic resistance and treatment failure ${ }^{[4]}$ Drugs that are used treat in combination are Carbapenems, Beta lactamase inhibitor, Tigecycline, Aminoglycosides, Polymyxins, Rifampin and Fosfomycin. ${ }^{[5-8]}$ Studies have shown that sensitivity of Trimethoprim - Sulfamethoxazole (TMP-SMX) ranges from $0 \%$ to $73.2 \%$ for the treatment of Acenatobacterbaumannii. ${ }^{[9]}$ Our case report describes successful treatment with Trimethoprim - Sulfamethoxazole and Polymyxin or Meropenem. This combination can become anexcellent treatment option in this era of increasing antibiotic resistance and lack of newer antibiotic for MDR pathogen.

\section{CASE PRESENTATION}

\section{Case 1}

A 67 year oldmale, with past history of chronic obstructive airway disease, accompanied by his son, presented at the Emergency Department of General Superspeciality Hospital, Birtamode, Nepal. He had alleged history of trauma by car and sustained injury over face, chest, left upper and lower limb with Injury Severity Score of 35.

At the time of admission to the emergency department his GCS was $13 / 15$, pulse rate 140 beats per min, blood pressure $80 / 60 \mathrm{~mm} \mathrm{Hg}$, respiratory rate 40 breaths/min and oxygenation saturation $82 \%$ on 10 liter of oxygen. Chest examination showed bilateral decrease air entry and crepitation. Abdominal examination showed generalized abdominal tenderness, with guarding and rigidity at left subcostal and lumbar region. Arterial blood gas analysis showed PH 7.21, partial pressure of oxygen $\left(\mathrm{PaO}_{2}\right) 56 \mathrm{~mm}$ $\mathrm{Hg}$, partial pressure of carbon dioxide $\left(\mathrm{PaCO}_{2}\right) 38 \mathrm{~mm} \mathrm{Hg}$, lactate $8 \mathrm{mmol} / \mathrm{L}$ and bicarbonate $15 \mathrm{mEq} / \mathrm{L}$.

An emergency physician and paramedics immediately resuscitated him by inserting 16 gauze cannula, central venous catheter and giving two litres of balanced salt solution Kabilyte (Fresenius Kabi, Pune,India). Intubation was done with $7 \mathrm{~mm}$ endotracheal tube.

Chest x-ray showed bilateral infiltrates, left hemopneumothorax and left scapular fracture. Focused Assessment with Sonography for Trauma (FAST) was positive. Contrast enhanced computed tomography of chest and abdomen showed bilateral lung contusion with left sided hemopneumothorax and grade 4 splenic injury with moderate hemoperitoneum respectively.

His investigation profiles were total leucocyte count (TLC)$21000 / \mathrm{mm}^{3}$; platelets- $90000 / \mathrm{mm}^{3}$; haemoglobin $(\mathrm{Hb})-7$ $\mathrm{gm} / \mathrm{dl}$; urea- $108 \mathrm{mg} / \mathrm{dl}$; creatinine- $1.8 \mathrm{mg} / \mathrm{dl}$. Sodium and potassium was $138 \mathrm{mmol} / \mathrm{L}$ and $4.9 \mathrm{mmol} / \mathrm{L}$, respectively. Liver function test showed bilirubin- $4 \mathrm{mg} / \mathrm{dl}$; Direct bilirubin- $1.6 \mathrm{mg} / \mathrm{dl}$; Total protein 6.4- $\mathrm{mg} / \mathrm{dl}$; albumin- 2.8 $\mathrm{mg} / \mathrm{dl}$; alanine aminotransferase (ALT)-368 U/L; and aspartateaminotransferase(AST)- $561 \mathrm{U} / \mathrm{L}$.

Emergency splenectomy and left chest tube insertion were performed and resuscitation was carried out with eight pint of whole and fresh blood and Noradrenaline at 0.1 $\mu \mathrm{g} / \mathrm{kg} / \mathrm{min}$ (Troikaa Pharmaceuticals Pvt, Ltd., Ahmedabad, India) was done. Patient was started on Pipercillin -Tazobactam 4.5 gram intravenous every eight hours (Aristo Pharmaceutical Pvt.Ltd., Mandideep, India) and Levofloxacin $750 \mathrm{mg}$ intravenously once a day (Glenmark Pharmaceuticals Ltd. Baddi, India).

Patient was extubated on third day of admission. Patient developed shortness of breath, fever with maximum temperature of $102^{\circ} \mathrm{F}$ and cough after eighth day of admission. TLC was $23000 / \mathrm{mm}^{3}$ Chest x-ray showed bilateral chest infiltrate with right sided pleural effusion (Figure 1) and urine examination showed pus cell plenty. Patient was started on Meropenem 1 gram intravenously 8 hourly (Sun Pharmaceutical Industries Ltd. Mumbai, India) and Doxycycline 100 mg every 12 hours (Gufic Biosciences Limited, Mumbai, India). There was no improvement in patient. Culture report of sputum and urine both showed Acinetobacter baumannii sensitive to Polymyxin B, Colistin and TMP-SMX. Patient was started on Polymyxin B 1.5 million units intravenously stat and 1 million units intravenously 2 times a day (Bharat Serums And Vaccines Limited, Mumbai, India) and TMP-SMX $(160+800 \mathrm{mg}) 2$ tablet per oral 12 hourly(Medico Remedies Ltd, Mumbai, India) for 10 days. He was discharged from hospital on the twenty second hospital day.

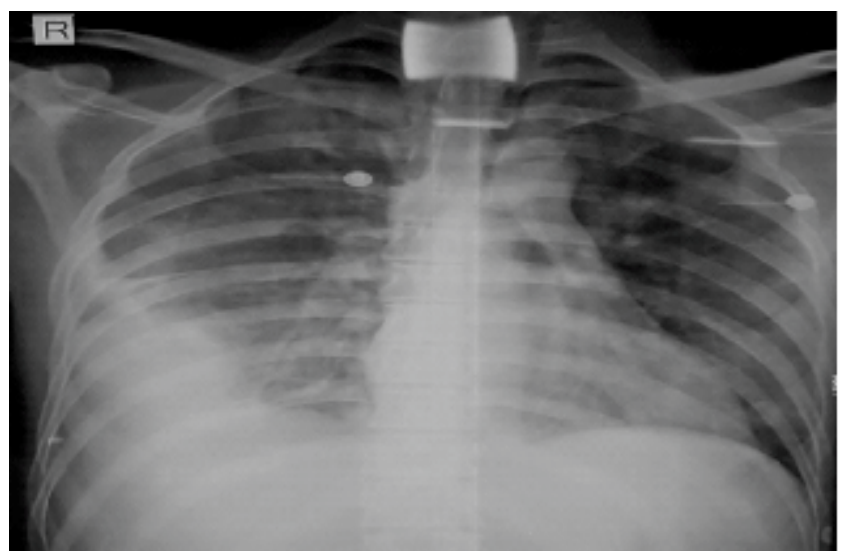

Figure 1: Chest X-ray anteroposterior view showing bilateral infiltrates with right sided pleural effusion

One week following discharge, he presented at the outpatient department for a follow up. His urine and chestray was normal.

\section{Case 2}

A 56 year old male, chronic alcoholic, smoker, diabetic accompanied by his son, presented at the Emergency Department of General Superspeciality Hospital, Birtamode, Nepal. He presented with complains of fever, cough, shortness of breath and abdominal distension for 4 days. 
At the time of admission to the emergency department his GCS was $14 / 15$, pulse rate 136 beats per min, blood pressure $84 / 56 \mathrm{~mm} \mathrm{Hg}$, respiratory rate 48 breaths/ min and oxygenation saturation $92 \%$ on 15 liter of oxygen. Chest examination showed bilateral crepitation. Abdominal examination showed generalized distension of abdomen with hepatosplenomegaly and shifting dullness. Arterial blood gas analysis showed $\mathrm{PH} 6.78$, partial pressure of oxygen $\left(\mathrm{PaO}_{2}\right) 58 \mathrm{~mm} \mathrm{Hg}$, partial pressure of carbon dioxide $\left(\mathrm{PaCO}_{2}\right) 21 \mathrm{~mm} \mathrm{Hg}$, lactate $14 \mathrm{mmol} / \mathrm{L}$ and bicarbonate 5 $\mathrm{mEq} / \mathrm{L}$.

An emergency physician and paramedics immediately resuscitated him by inserting 16 gauze cannula, central venous catheter and giving two litres of balanced salt solution Kabilyte (Fresenius Kabi, Pune,India), Noradrenaline (Troikaa Pharmaceuticals Pvt, Ltd., Ahmedabad, India) and Sodium bicarbonate at $25 \mathrm{ml}$ per hour. Intubation was done with $7.5 \mathrm{~mm}$ endotracheal tube.

Patient was started on Pipercillin-Tazobactam 4.5 gram intravenous every eight hours (Aristo Pharmaceutical Pvt.Ltd., Mandideep, India) and Levofloxacin $750 \mathrm{mg}$ intravenously once a day (Glenmark Pharmaceuticals Ltd. Baddi, India)

His investigation profiles were total leucocyte count (TLC) $3100 / \mathrm{mm}^{3}$; platelets- $60000 / \mathrm{mm}^{3}$; haemoglobin $(\mathrm{Hb})-8$ gm/dl; urea- $276 \mathrm{mg} / \mathrm{dl}$; creatinine- $5.7 \mathrm{mg} / \mathrm{dl}$. Sodium and potassium was $130 \mathrm{mmol} / \mathrm{L}$ and $5.3 \mathrm{mmol} / \mathrm{L}$ respectively. Liver function test showed bilirubin- $6.4 \mathrm{mg} / \mathrm{dl}$; Direct bilirubin- $4.1 \mathrm{mg} / \mathrm{dl}$; Total protein 6.4- mg/dl; albumin- 2.6 $\mathrm{mg} / \mathrm{dl}$; alanine aminotransferase (ALT)- $1564 \mathrm{U} / \mathrm{L}$; and aspartate aminotransferase (AST)- $1867 \mathrm{U} / \mathrm{L}$.

Blood investigation IgM /IgG formalaria, dengue, scrub typus, enteric fever and leptospira were normal. Ultrasound of abdomen and pelvis showed hepatosplenomegaly, bilateral enlarged kidney, ascites and pneumonia. Patient was extubated on second day of admission.

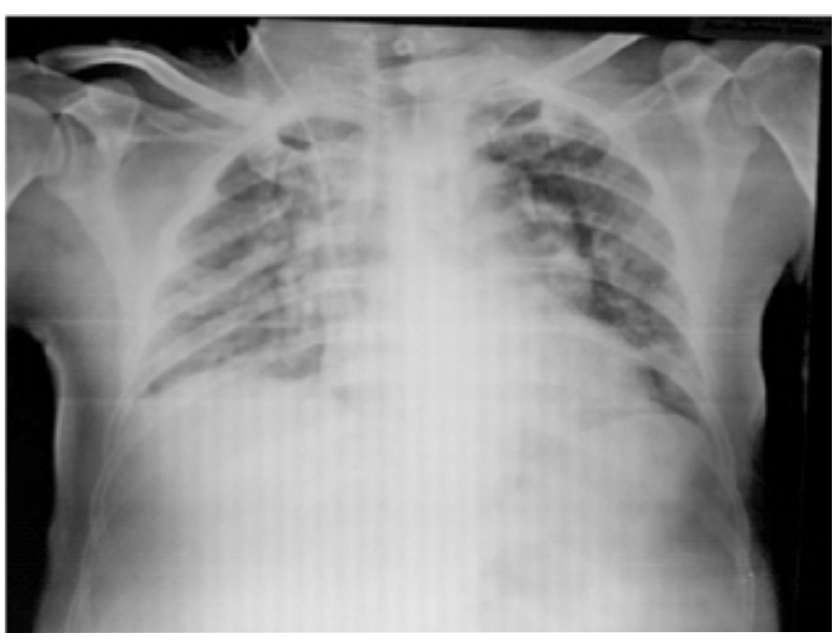

Figure 2: Chest X-Ray anteroposterior view showing bilateral infitrates
Patient developed fever with maximum temperature of $102.5^{\circ} \mathrm{F}$, cough and burning micturition on fifth day on admission in ICU.Blood investigations showed TLC of $18000 / \mathrm{mm}^{3}$ with neutrophil predominance and creatinine $8 \mathrm{mg} / \mathrm{dl}$. Sputum and urine culture report showed Acinetobacter baumannii sensitive to Meropenem and TMPSMX. Patient was started on Meropenem 500 mg intravenously two times a day (Sun Pharmaceutical Industries Ltd. Mumbai, India) and TMP-SMX (160+800 mg) 1 tablet per oral 12 hourly (Medico Remedies Ltd, Mumbai, India) for 10 days. Serum creatinine was monitored daily and was noted to be in decreasing trend until it became normal on the fifteenth day of admission (Figure 3). He was discharged from hospital on the twenty eighth hospital day.

One week following discharge, he presented at the outpatient department for a follow up. His urine routine examination and chest $\mathrm{x}$-ray were normal.

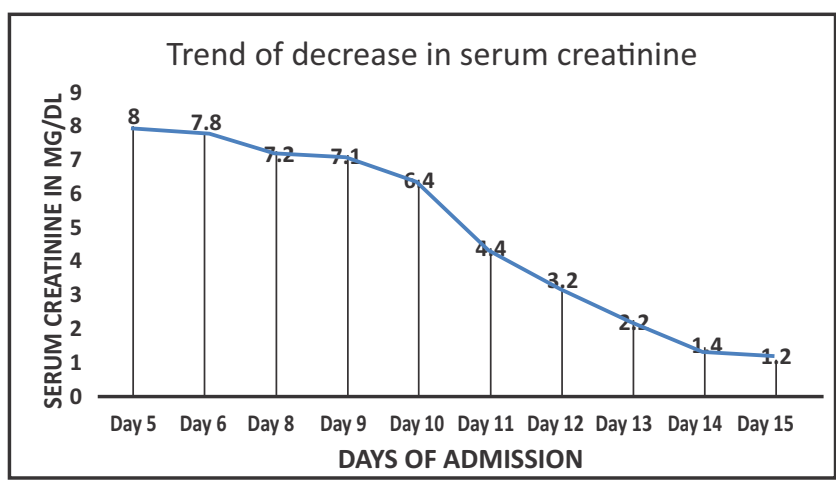

Figure 3: Line graph showing trend in decrease in serum creatinine

\section{Case 3}

A 21 year old male, without any significant past history, presented at the Emergency Department of General Superspeciality Hospital, Birtamode, Nepal. He had alleged history of trauma by truck and sustained injury over head, face and chest with Injury Severity Score of 40 .

At the time of admission to the emergency department his GCS was $3 / 15$, and his pupils were not reactive to light, pulse rate 160 beats per min, blood pressure 70/60 mm Hg, respiratory rate 40 breaths/ $\mathrm{min}$ and oxygenation saturation $72 \%$ on 10 liter of oxygen. Chest examination showed bilateral decrease air entry and crepitation. Abdominal and cardiovascular examination was normal. Arterial blood gas analysis showed $\mathrm{PH} 7.11$, partial pressure of oxygen $\left(\mathrm{PaO}_{2}\right)$ $58 \mathrm{~mm} \mathrm{Hg}$, partial pressure of carbon dioxide $\left(\mathrm{PaCO}_{2}\right) 26 \mathrm{~mm}$ $\mathrm{Hg}$, lactate $10 \mathrm{mmol} / \mathrm{L}$ and bicarbonate $21 \mathrm{mEq} / \mathrm{L}$.

An emergency physician and paramedics immediately resuscitated him by inserting 16 gauze cannula, central venous catheter and giving two liters of balanced salt solution Kabilyte (Fresenius Kabi, Pune,India).Intubation was done with $7 \mathrm{~mm}$ endotracheal tube.

Chest $\mathrm{x}$-ray showed bilateral infiltrates, hemopneumothorax. Extended Focused Assessment with Sonography for Trauma (FAST) was positive. Contrast enhanced computed tomography 
of head and chest showed bilateral subdural hematoma with subarachnoid hemorrhage and bilateral lung contusion with hemopneumothorax respectively.

His investigation profiles were total leucocyte count (TLC) $11000 / \mathrm{mm}^{3}$; platelets- $750000 / \mathrm{mm}^{3}$; haemoglobin $(\mathrm{Hb})-9$ $\mathrm{gm} / \mathrm{dl}$; urea- $108 \mathrm{mg} / \mathrm{dl}$; creatinine- $2.8 \mathrm{mg} / \mathrm{dl}$. Sodium and potassium was $138 \mathrm{mmol} / \mathrm{L}$ and $4.9 \mathrm{mmol} / \mathrm{L}$, respectively. Liver function test showed bilirubin-1.8mg/dl; Direct bilirubin- $1.2 \mathrm{mg} / \mathrm{dl}$; Total protein 6.4- $\mathrm{mg} / \mathrm{dl}$; albumin- 3.8 $\mathrm{mg} / \mathrm{dl}$; alanine aminotransferase (ALT)- $168 \mathrm{U} / \mathrm{L}$; and aspartate aminotransferase(AST)- $68 \mathrm{U} / \mathrm{L}$.

Chest tube was inserted bilaterally and resuscitation with two pint of whole and two pint fresh blood and noradrenaline at $0.1 \mu \mathrm{g} / \mathrm{kg} / \mathrm{min}$ (Troikaa Pharmaceuticals Pvt, Ltd., Ahmedabad, India) was done. Patient was started on Pipercillin-Tazobactam 4.5 gram intravenous every eight hours (Aristo Pharmaceutical Pvt.Ltd., Mandideep, India) and Levofloxacin $750 \mathrm{mg}$ intravenously once a day (Glenmark Pharmaceuticals Ltd. Baddi, India).

Chest tube was removed on the third day of admission. However, there was no improvement in GCSand he developed increased secretion and fever with maximum temperature of $101^{\circ}$ Fon the fifth day of admission in ICU. Chestx-ray was done which showed bilateral infiltrate (Figure 4). Blood investigation showed TLC of $24,000 / \mathrm{mm}^{3}$. Tracheal aspirate showed Acinetobacter baumannii sensitive Polymyxin B, Colistin and TMP-SMX. Patient was started on Polymyxin B 1.5 million units intravenously stat and 1 million unit intravenously 2 times a day (Bharat Serums And Vaccines Limited, Mumbai, India) and TMPSMX (160+ $800 \mathrm{mg}) 2$ tablet per oral 12 hourly (Medico Remedies Ltd, Mumbai, India) for 10 days. Tracheostomy was done on tenth day of admission. He was discharged from hospital to long term care facility on fifteenth day of hospital admission.

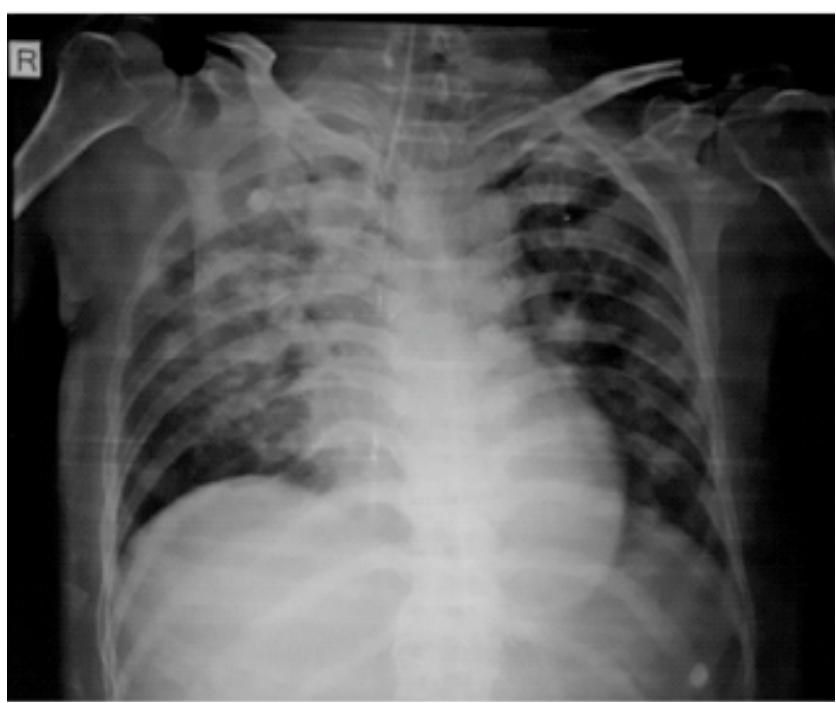

Figure 4: Chest X-Ray showing bilateral infiltrates, more on the right.
Summary of clinical and laboratory characteristics of all three cases are presented in table 1.

Table 1. Patients' characteristics - demographics, clinical and laboratory characteristics

\begin{tabular}{|l|c|c|c|}
\hline & Case $\mathbf{1}$ & Case $\mathbf{2}$ & Case $\mathbf{3}$ \\
\hline Age (Years) & 67 & 56 & 21 \\
\hline Gender & Male & Male & Male \\
\hline Fever (Max) & $102^{\circ} \mathrm{F}$ & $102.5^{\circ} \mathrm{F}$ & $101^{\circ} \mathrm{F}$ \\
\hline Heart rate $>90 /$ minute & Yes & Yes & Yes \\
\hline Respiratory rate $>20 /$ minute & Yes & Yes & Yes \\
\hline Cough & Yes & Yes & Intubated \\
\hline Shortness of breath & Yes & No & Intubated \\
\hline Burning Micturation & No & Yes & No \\
\hline Total Leucocyte Count & $23000 / \mathrm{mm}^{3}$ & $18000 / \mathrm{mm}^{3}$ & $24000 / \mathrm{mm}^{3}$ \\
\hline $\begin{array}{l}\text { New developed infiltrates on } \\
\text { chest } x \text {-ray }\end{array}$ & Yes & Yes & yes \\
\hline
\end{tabular}

\section{DISCUSSION}

Gram negative infection is more common in developing country[10] ICU and incidence ranges from 47 to $84 \%$. [10] Acinetobacter baumanniiis a MDR bacteria and incidence ranges from 13 to $41 \%$ [11-13] and mortality is very high up to $81 \%$. ${ }^{[11-13]}$

Acinetobacter baumannii infection generally occurs in patient that have risk factor like recent hospitalization, poor general medical condition, mechanical ventilation, cardiac or respiratory failure, antibiotic therapy and presence of central venous or urinary catheter that leads to emergence of a multidrug resistant Acinetobacter baumannii. Meropenem, Imipenem, Doripenem, Polymyxin B, Colistin is used in combination with Rifampin,Tigecycline, Amikacin and fosfomycinfor treatment of Acinetobacter baumannii.

Studies have shown that sensitivity of TMP-SMX is different from hospital to hospital; ranges from $0 \%$ to $73 \% .^{[1,9,14]}$ Dose of TMP-SMX is unclear in critically ill patients for susceptible organism despite being older antibiotic. ${ }^{[15]}$ It can be given in oral or intravenous form ; can be given two times in noncritical patients but three or four times to avoid toxicity in critically ill patients. In our patient we used oral form as intravenous was not available at our center.

Newer drugs that can be used in future for Acinetobacter baumannii are Siderophore cephalosporins, Eravacycline, Apramycin, phage therapy. This newer drugs are expensive and arestill in clinical trial. ${ }^{[16]}$ Therefore, TMP-SMX can be used in combination for treatment of Acineto bacter baumannii based on sensitivity. ${ }^{[17-19]}$

\section{CONCLUSIONS}

TMP-SMX is older, cheaper easily available antibiotic that is available at primary health care center that can be used in combination with Polymyxin or Carbapenem for treatment of Acinetobacter baumannii. 


\section{REFERENCES}

1. Van Looveran M, Goossens H, ARPAC Steering Group. Antimicrobial resistance of Acinetobacter spp. In Europe. Clin Microbial Infect 2004;10(8):684-704.

2. Pailhories $H$, Belmonte $O$, Kempf $M$, Lemarie C, Cuziat J, Quinqueneau $\mathrm{C}$ et al. Diversity of Acinetobacter baumannii strains isolated in humans, companion animals, and the environment in Reunion Island: an exploratory study. Int J Infect Dis 2015;37:64-9.

3. Sengstock DM, Thyagarajan R, Apalara J, Mira A, Chopra T, Kaye KS. Multidrug-resistant Acinetobacter baumannii: an emerging pathogen among older adults in community hospitals and nursing homes. Clin Infect Dis 2010;50(12):1611-6.

4. Tuon FF, Rocha JL. Merlini AB. Combined therapy for multi-drugresistant Acinetobacter baumannii infection-is there evidence outside the laboratory?. J Med Microbiol 2015;64(9):951-9.

5. Maragakis LL, Perl TM. Acinetobacter baumannii: epidemiology, antimicrobial resistance, and treatment options. Clin Infect Dis 2008; 46(8):1254-63.

6. Fishbain J, Peleg AY. Treatment of Acinetobacter Infections. Clin Infect Dis 2010;1(1):79-84.

7. Michalopoulos A, Falagas ME. Treatment of Acinetobacter Infections. Expert OpinPharmacother 2010;11(5): 779-88.

8. Jung SY, Lee $S H$, Lee $S Y$, Yang $S$, Noh H, Chung EK et al. Antimicrobials for the treatment of drug-resistant Acinetobacter baumannii pneumonia in critically ill patients: a systemic review and Bayesian network meta-analysis.Crit Care 2017;21(1): 319.

9. Budayanti NS, Surandai IW, Tarini MA, Violentina GAD, Deva IDGS.Antimicrobial susceptibility patterns of Acinetobacter baumannii isolates from ICU and non-ICU wards.Bali Journal of Anesthesiology 2019;3(1): 50-54.

10. Keyal NK, Nakarmi M, Adhikari P. Polymyxin B and Doxycycline for Treatment of Multidrug Resistant Klebsiella Pneumoniae and Staphylococcus Aureus Pneumonia in Intensive Care Unit.BJHS 2019;4(2): 762-4.
11. Siwakoti S, Subedi A, Sharma A, BaralR,Bhattarai NR, Khanal B. Incidence and outcomes of multidrug-resistant gram-negative bacteria infections in intensive care unit from Nepal-a prospective study. Antimicrob Resist Infect Control 2018;7:114.

12. Garg VK, Mishra S, Gupta N, Garg R,SachidanandB,Vinod K et al. Microbial and Antibiotic Susceptibility Profile among Isolates of Clinical Samples of Cancer Patients Admitted in the Intensive Care Unit at Regional Tertiary Care Cancer Center: A Retrospective Observational Study. Indian J Crit Care Med 2019;23(2):67-72.

13. Sarvepalli AK, Dharana PK. Clinical profile, bacterial profile and outcomes in an intensive care unit of a tertiary care hospital in south India: one year study. International J Advances Medicine 2017;4(1): 156-61.

14. Bhattacharyya S, Bhattacharyya I, Rit K, Mukhopadhyay, DeyJB, Ganguly $U$ et al. Antibiogram of Acinetobacter spp. Isolated from various clinical specimens in a tertiary care hospital in West Bengal,India.Biomedical Research 2013;24(1):43-46.

15. Brown GR.Cotrimoxazole-optimal dosing in the critically ill. Ann Intensive Care 2014;4:13

16. Isler B, Doi $Y$, Bonomo RA, Paterson DL. New Treatment Options against Carbapenem-Resistant Acinetobacter baumannii Infections. AntimicrobAgents Chemother 2018;63(1)

17. Khalil MAF, Moawad SS, Hefzy EM. In vivo activity of co-trimoxazole combined with colistin against Acinetobacter baumannii producing OXA-23 in a Galleria mellonella model. J Med Microbiol 2019;68 (1):52-59.

18. Falagas ME, Vardakas KZ, Roussos NS. Trimethoprim/sulfamethoxazole for Acinetobacter spp.: A review of current microbiological and clinical evidence. Int J Antimicrob Agents 2015; 46(3): 231-41.

19. Farid $S$, Abouelela A, Eliwa M. Doxycycline and Co-trimethoxazole: $A$ new combination for treatment of MDR Acinetobacter baumannii. Does it work?.Int J Curr Microbiol App Sci 2016;5(1):157-64. 